\title{
HIV’s Counsellors in Hospitals, Between Health Profession and Associative Involvement
}

\author{
Mounsade Kpoundia Fadimatou \\ UMR SESSTIM-INSERM-IRD/Aix-Marseille Université, Marseille, IRSA/UCAC, Yaoundé
}

\begin{abstract}
The lay expertise is required to give psychosocial care to HIV patients in hospitals. Those HIV's counsellors, from HIV patients association are involved in care process. Unless, their status is still undetermined and their work appears as a mix of counselling, therapeutic education, social support, and testimony.
\end{abstract}

Keywords: AIDS (Acquired Immune Deficiency Syndrome), lay expertise, patient expert, psychosocial care, counsellors, care given

\section{Introduction}

To ensure an effective involvement of people who are concerned by HIV (Human Immune Deficiency Virus) in the fight against HIV/AIDS (Acquired Immune Deficiency Syndrome), the concept of community participation allows the HIV's patient to be integrated in care process. This insertion begins in community by the creation of support groups of PLWA (People Living With AIDS). In the end of 1980s, we witnessed a shy creation in Africa of associations of PLWA (TASO (The AIDS Support Organisation) in Uganda in 1989, SWAA (Society for Women and AIDS in Africa) in 1990 in West and Central Africa, AFSU (Association des Frères et Soeurs Unis) in 1994, and AFASO (Association des Femmes Actives et Solidaires (Association of Women living with AIDS)) in 1998, both in Cameroun).

The associative help in community produced good results according to the acceptance of illness and the socialisation of the HIV's infected person. Because it is difficult to identify a person who lives with AIDS just on sight, the leaders of associative actions against AIDS decided to follow up HIV's infected from the hospitals where their serology status is screened. Associative activities in hospitals help PLWA to gather in associations. From association where they are members, HIV's patients arrive in hospital as counsellors and have a psychosocial role to ensure in therapeutic.

The aim of this paper is to analyse this participation of PLWA in the therapeutic system not as a patient, but as a person who is able to take care of other patients. The analysis is based on anthropological data, collected during Ph.D. researches on field in five regions in Cameroon, where about 200 respondents chosen in staff of care given to HIV's infected have been observed and interviewed in 15 health centres and 24 associations of PLWA working with those hospitals.

This paper exposes how HIV patients are recruited in staff in hospitals, and it analyses the impact of this participation on the association where the associative staff come from and also the impact on medical care.

Mounsade Kpoundia Fadimatou, Ph.D. student, UMR SESSTIM-INSERM-IRD/Aix-Marseille Université. 


\section{The Arrival of HIV Counsellors in Hospitals in Cameroon}

\section{The Involvement in Therapeutic}

The insertion of patient as counsellor in the health care system, observed in the beginning of the 1990s, results from the concept of "community participation". The concept allows the full involvement of concerned people on its own development. So that, PLWA are the first motor of the fight against AIDS and as was the theme of HIV's Paris Summit 1994 "the greater involvement of people living with AIDS", PLWA have to be associated to any step of decisions about their conditions (UNAIDS, 1999). The main view behind this involvement is the experience of life with disease. PLWA, because they have experienced life with HIV, are supposed to have some personal and intimate knowledge on the disease.

In Cameroon, the community participation permits to consider HIV's patient as somebody who can help other HIV infected people to go through the illness. According to the National plan for the fight against AIDS, the HIV patient should be associated to the therapeutic system in HIV centre care for a psychological assistance to other HIV patients. This integration should be read in two ways, first a disguised request of HIV centres, and secondly, as an associative request.

\section{A Disguised Request of HIV Health Centres}

In the end of the1990s, Cameroon was confronted with an expansion of HIV infection in its population (Gruenais, 2006). The public health policies were downed by stigmatisation and discrimination of people screened positive for HIV. To control the pandemic, the ministry of public health allowed HIV centres to help HIV infected people to gather together. By this, the associative movement of PLWA was installed in HIV health centres. The centres, between their patients, chose one patient as therapeutic model of acceptance of living with AIDS and a follow-up of therapeutic given in hospital. These selected HIV patients were motivated and enrolled as counsellors in the care staff for HIV therapy, helping for bring people to screen and announce the HIV screen result to people. They also had to promote HIV patients meeting around a mutual support and assistance between members of group.

In 2000, we notified few associations (SWAA, AFASO, AFSU, and SUNAIDS) implanted in hospitals. They were more and more financially supported by international non-government organisation and the Global Fund for fight against HIV/AIDS. Because of the liberty of associations of 1990, state subvention and the financial support from NGO (Non Governmental Organization), the number of associations for help to HIV infected people and fight against AIDS raised from four in 2000 to about 100 in recent years. Their intervention in care permits also to reduce the lack of care given staff in HIV health centres. Psychosocial care appears as a task shift to association’s staff.

\section{An Associative Request}

The intervention in hospitals finally appears as an important strategy for associations. They organised themselves in hospitals and worked with those hospitals. Following the decentralization of HIV health centres, and supported first by a GIZ (German Cooperative Organization), the associations organise themselves and their members, as counsellors, integrate conventionally or not, the therapeutic care. This formal presence in health centres, motivate patients to be interested on association activities. As a respondent in charge of an association told, "Patients come to association, not just for assistance and sharing their suffering, they think association will find out a job for them". Association becomes a way to have a job and regarding the number of associations, have a convention with hospitals becomes a challenge. 
Integrating therapeutic care by hospital's request or by own associative request, associative members arrive as counsellors. Between 2000 and 2004, only the associations have been involved in psychosocial support to HIV patients in hospitals. Counselling to HIV patients seems their privilege role or job in patient care process.

The association member's activities in therapy process depend on the relation between the institutions, association and health care for HIV. The treatment of association's staff lay on financial project on HIV/AIDS. Those workers were unsatisfied with the way they have been managed by their leader, and, today because of the lack of professional status of their activities in care process. The leaders retained $10 \%$ or $15 \%$ of their work compensation to ensure the on-going of the association. Other way, their professional status still be uncertain, sometimes volunteers and some else time they perceive a compensation, not a salary. According to the importance of association's activities in HIV therapy and trouble in organising association activities in hospitals triggered a state reaction by a recruitment of another kind of counsellor, called ARC (Agents Relais Communautaire).

\section{ARC, a Government Reaction}

In 2005, five years after the institutionalisation of HIV therapies in hospitals in Cameroon, the State decided to recruit staff in charge of psychosocial support in HIV health centres. ARCs were recruited by the State to ensure psychosocial care and community release between HIV/AIDS care centres and the community.

The second recruitment took place in 2007. Those 2005 and 2007 recruitments break with the tradition of psychosocial staff, coming from association of fighting against HIV/AIDS. The profiles of the ARC are diverse as those of the associative staff. Their background is a basics training in social work, nursing, or they are students in psychology. And the experience of living with AIDS did not influence the criteria of recruitment.

But only, the arrival of these ARC aroused conflicts of interests between them and the associative staff already in position. The argue concerned workspaces. ARCs were affected on the whole national territory, where associations exercise for a little more than five years, without, at the level of the structures of care, an official professional recognition. In the community, the associative staff have more audience among the PLWA because of their closeness and their regularity on the ground. ARCs, who have an institutional legitimacy of the vocational trainings of schools legally recognized by the State, claimed and required more seriousness towards them. They estimate that the associative members are involved just to testify an HIV life experience and in make other PLWAs go through the hard moments of the announcement of HIV serology.

In September 2009, the activities of the ARCs are suspended according to an individual informative letter, for lack of financial resources. A few months later, for the duration of four not renewable months, the activities started again, this time under the aegis of Care-Cameroun, an association for fight against AIDS. So, ARCs contracts have been passed via associations. That means, finally to be in psychosocial staff in charge of counselling to HIV patient, to be an association's member is a most important criteria.

Since June 2011, we witnessed a shy resumption of the activities of the ARC, who, in spite of the suspension of the activities stayed in office for 2009 according to a respondent, because they hoped a reemployment. Their status, as counsellor's status, also depends on financial project in HIV/AIDS.

The context and the status of that ARC, relieve two facts in the HIV patient enrolment in the therapy. First, the cadence on the recruitment between associations and individuals contracts seems to show that the involvement was not well understood and implemented and also it is an associative engagement. The second fact is that, considering psychosocial activities a regular job, their work conditions have to be improved. 


\section{HIV Counsellors Activities in Hospital's Care Given Against HIV/AIDS}

HIV counsellor's activities in hospital are presented as a psychosocial follow-up of PLWA which contents therapeutic education about drugs taken, counselling, releasing between hospitals and community and testifying. The main target of psychosocial care is to help the person infected by HIV to live positively by facing the vulnerability.

\section{Counselling}

Counselling is a discussion between a counsellor and a customer about the HIV infection (transmission, prevention and life without and with HIV). It has three steps, pre, before the screening, post, while withdrawing the screen results, and the follow-up for those who need the therapy. The main target of counselling is to make people have self-control in front the HIV vulnerability. Some authors distinguish profane counsellors and professional counsellors (Bureau, 2010; Tourette-Turgis, 1996). The profane counsellor is a member of the community as an association member who is common volunteer. He is work on a project and is not considered as a health professional even though he does and has a lot to do in therapy process (Bureau, 2010). Counselling should also be done by a doctor or a paramedical. In Cameroon context, professionals are too busy and counselling is in charge of HIV counsellors.

\section{Therapeutic Education}

It's education on taking treatment and life with HIV, side effects of drugs and adherence. During a therapeutic education, many topics on HIV/AIDS are developed by counsellors and discussed with HIV patients. The target is to inform and communicate about the HIV (Niemann, 1995) and also show or give good practises on life with HIV. In many HIV health centres, the social assistants are also involved. They were associated by the past when ART were not free. They had to identify between patients the indulgency cases for be helping.

\section{Releasing Between Hospitals and Community}

Because of social and economic vulnerability individual and community due to HIV, PLWA or affected one's, have to be followed in their community in way to help them socialize and live. For that, know the context of each patient should give keys of his therapeutic follow up. HIV's counsellors to good follow-up ensure the release between community and hospitals where HIV's patients are followed. Today this activity has a lot of problems due to the lack of financial projects. ARC PPTE activities are suspended, associations look forward projects able to ensure their functioning.

\section{Testimony}

This activity is only done by counsellors because of their experience life with HIV. It is consisted on declaring the HIV's status publicly. The role of testimony is to show to others HIV positive that life is possible with AIDS. It is the practice or the sharing of HIV's life experience. Health professionals (doctors and paramedical) interviewed present the testimony as the main target of the integration of counsellor in hospitals. This consideration reduces HIV's counsellors activities to a publicly declaration of their HIV's status. In that way their experiential HIV's knowledge seem as a skill which makes HIV's counsellor able to integrate the therapy follow-up of PLWA in hospitals.

\section{The Involvement and Its Effects}

The most impact of the psychosocial staff is lead by professional requests. If it is today sure that 
psychosocial care given improves the health offer to PLWA (Eboko, Christian, \& Abé, 2010; Delbanco et al., 2000), the staff is still expecting a consideration of their activities as a job and an improvement of their status.

\section{The Career in Health Professions}

Both categories of HIV's counsellors on field (members of association and those were recruited by the State) have an atypical contract of employment which corresponds to any model expressed by the labour code or by the public service code. The ARCs contract stipulates that it is a convention of hiring service of six months renewable, which giving the right to a compensation. But only, "The contract of employment is a convention by which a worker makes a commitment to put his professional activity under the authority and the direction of an employer, in return of a remuneration" (Cameroonian labour code, Article 23. 1). But concerning the remuneration of the activity of HIV's counsellors, we speak rather about a compensation of their professional activity. Sometimes, they work as volunteers, another time as salaries depending on financial project. The professional relation, in particular, for the case of the members of association, is established neither with the sanitary structure nor with the organ administrator of the project. Besides, the play on words does not allow to specify the nature of contract, here we speak about hiring of service, referring to the French Civil Code by 1708 of which is inspired the Cameroonian Labour Code, is a contract of employment. We are in front of the unconscious production of an informal in the formal in development projects. Through the words, HIV's counsellors are recruited and affected in HIV's health care centres, by associative way or by individual and personal negotiation, we can notice an absence of real politics of their professional career. Even HIV's counsellors recruited by the State, do not have a clear specific career profile. In 2009, to restart their activities after an economic break cause of a lack of functioning resources (Bestley \& Ghathak, 2008), those counsellors were been consider as associative members. In that way, they were able to benefit the HIV's project closes about the community participation

\section{The Status of HIV's Counsellors}

In a descriptive way, every person practicing care given for the promotion of the health and working in a hospital is an actor of care. The care given actors as notices (Strauss, 1985) are governed by a hard social net. The hospital is much professionalized and where several categories of staffs are involved. The HIV/AIDS care brings a break in the culture of the health profession, usually organized around the medical activities (Carricaburu \& Menoret, 2004). The traditional actors of care given are two orders, the doctors and the paramedical. Freidson (1984, p. 57) includes under the word paramedical all the jobs which fall under the control of the medical activity. These jobs cannot be applied without the medical order. We attend a break because of the introduction of a new corporate association beyond the simple necessity of new skills: The psychosocial is insured by relay agents community, the associative staff and the social workers. These jobs do not find a place in an environment where the organization chart and the hierarchy are at the heart of the organization

The conditions of integration of these new staffs create consistently a break in the modes of recruitment with the insertion of a not competent and not trained staff on the basis of the social representations of the disease in the therapeutic field (Mounsadé Kpoundia, 2008; Tantchou \& Gruenais, 2009). The cultural changes don’t drive mutations in professional identities in hospitals.

The actor fitted into the circuit of the patient and not into the professional ID card. Any professional course does exist for the training of HIV's counsellors and others psychosocial care given except social 
assistance. No formal career plan is seen. We attend a personal seek of employability of the actors in particular on the association's staff who, according to the projects and to the visibility of the association, can multiply contract in a field varied (ARC by state recruitment, counsellor in another institution than hospital or therapeutic educational). The place of the lay expertise is thus function of the role and the status of the actor. If the association's staff sees a professional hospital activity there, the other actors of care read on only a social strategy of improvement of the quality of PLWA care given in hospitals. The involvement of lay expertise improve the quality of offer of care (UNAIDS, 1999; Eboko et al., 2010), but, we can question the logics of implementation of this patient expertise in therapeutic given. HIV's counsellor, move from association activism to a professional area because of the serological status. If it is important to consider the HIV's experience of life, can a job be built around it? The professionalization includes skills and knowledge whose make able to do the job. The experience is important but not sufficient to develop a job.

\section{Conclusion}

The main observation is that the integration of HIV counsellors from association affects the patient relationship in care. Regarding the counselling step, the patient begins as customer (the pre-test) and when after the HIV screen if he/she is diagnosed HIV infected, he/she become a patient. He/she should be an ill or not patient. Depending on its role in the care process, the patient qualification is diverse. As HIV's counsellor who testifies of his life experience with HIV, the patient is called patient expert or expert profane. This influences the understanding of the notion of care. Is the expertise profane a care activity or an association's activity? Is it a relationship between a patient with its experience knowledge or an institutional relation between association and hospitals among HIV care to PLWA?

\section{References}

Bestley, T., \& Ghatak M. (2008). Provision of public services by Non-state actors. Revue d'économie de développement, 4(22), 89-108.

Bureau E. (2010). Anthropology of a global norm, lay participation in AIDS programmes in Cambodia (Doctoral dissertation, Université Victor Segalen Bordeaux II).

Carricaburu \& Menoret. (2004). Sociologie de la santé, institutions, professions et maladies (Health sociology, institutions, profession and disease). Paris: Armand Colin.

Delbanco et al. (2001). Health care in a land called peoplepower: Nothing about me without me. Health expectations, 4, $144-150$.

Gruénais, M. E. (2006). Changing a health system: Cameroon case. APAD.

Eboko, F., Christian, L., \& Abe, C. (2010). Decentralised access to HIV/AIDS treatment, evaluation of the Cameroon experience. ANRS Editions.

Eboko et al. (2011). South against AIDS, civil society mobilization. Collection objectives, Paris IRD Editions.

Freidson. (1984). La profession médicale (Profession of medicine). Paris, Payot.

Mounsade, K. F. (2008). Organization of HIV/AIDS care given and staff involvement (Master's thesis, Université Catholique d'Afrique Centrale, Yaoundé).

Niemann, F. (1995). Pro-dialog: Human relation consulting. Germany: ESSEN.

Strauss, A. (1985). Social organization of medical work. Chicago: University of Chicago Press.

Tantchou, Y. J., \& Gruenais, M. E. (2009). Involving new actors to achieve ART scaling-up: Difficulties in an HIV/AIDS counselling and testing centre in Cameroon. International Council of Nurses, 56(1), 50-57.

Tourette-Turgis, C. (1996). The counselling. Paris, Que sais-je.

UNAIDS. (1999). From principle to practise: Greater involvement of people living with or affected by HIV/AIDS: Best practice key material.

WHO. (1998). Patient therapeutic education. 